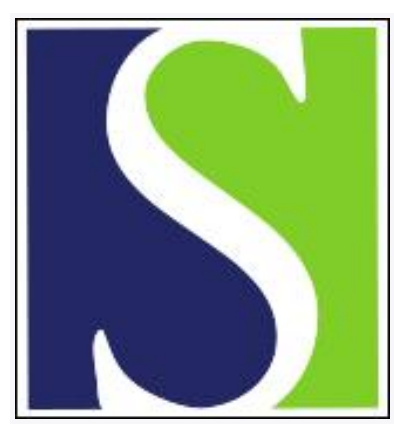

Scand J Work Environ Health 2004;30(5):371-378

https://doi.org/10.5271/sjweh.825

Issue date: Oct 2004

\title{
Biological monitoring of exposure to toluene diisocyanate
}

by Sennbro CJ, Lindh CH, Tinnerberg H, Welinder H, Littorin M, Jönsson BAG

Affiliation: Institute of Laboratory Medicine, Department of Occupational and Environmental Medicine, University Hospital, S-221 85 Lund, Sweden. carl-johan.sennbro@ymed.lu.se

The following articles refer to this text: $2005 ; 31(1): 84$;

2007;33(4):280-285

Key terms: biological exposure index; biological monitoring; biomarker; exposure; occupational exposure limit; polyurethane; protein adduct; toluene diisocyanate

This article in PubMed: www.ncbi.nlm.nih.gov/pubmed/15534959

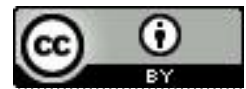




\title{
Biological monitoring of exposure to toluene diisocyanate
}

\author{
by Carl Johan Sennbro, MSc, ${ }^{1}$ Christian H Lindh, PhD, ${ }^{1}$ Håkan Tinnerberg, PhD, ${ }^{1}$ Hans Welinder, PhD, ${ }^{1}$ \\ Margareta Littorin, MD, ${ }^{1}$ Bo AG Jönsson, $P h D^{1}$
}

\begin{abstract}
Sennbro CJ, Lindh CH, Tinnerberg H, Welinder H, Littorin M, Jönsson BAG. Biological monitoring of exposure to toluene diisocyanate. Scand J Work Environ Health 2004;30(5):371-378.
\end{abstract}

\begin{abstract}
Objectives Toluene diisocyanate (TDI) is used in the manufacture of polyurethane and is a potent inducer of diseases of the airways. In this study, 2,4- and 2,6-toluenediamine in hydrolyzed urine and plasma were evaluated as biomarkers of exposure to 2,4- and 2,6-TDI, respectively.

Methods For 81 exposed workers from nine different plants, the personal 8-hour time-weighted-average exposure to TDI was monitored by a filter method with 1-(2-methoxyphenyl)piperazine. In parallel, urinary samples (U1) were collected during the last 4 hours of the workshift. On a different occasion, blood samples and additional urinary samples (U2) were collected from the exposed workers, and also from a reference group consisting of 121 unexposed workers. The biomarker levels were determined in urine and plasma by the use of alkaline hydrolysis.

Results There were strong associations between the personal air and biomarker levels, with correlation coefficients in the range of $0.75-0.88$ for the U1 samples and in the range of $0.50-0.78$ for the plasma samples. By weighted linear regression, the relations were calculated between the air and biomarker levels. The slopes of the obtained regression curves ranged from 1.8 to $2.7 \mathrm{~m}^{3} / 1$ for air-urine and from 2.2 to $2.9 \mathrm{~m}^{3} / 1$ for air-plasma, and the intercepts were all close to the origin of the coordinates. Through the extrapolation of these regression curves, biological exposure limits were calculated.

Conclusions The biological monitoring methods and strategies presented in this report are useful for assessing exposure to TDI in practice.
\end{abstract}

Key terms biological exposure index, biomarker, occupational exposure limit, polyurethane, protein adducts.

Toluene diisocyanate (TDI) is extensively used in the manufacture of polyurethane products and is mainly used as an 80:20 mixture of the two isomers 2,4-toluene diisocyanate (2,4-TDI) and 2,6toluene diisocyanate (2,6-TDI) (1). TDI is a respiratory irritant and may also cause chronic disorders of the airways, such as occupational asthma (2-4), and, hence, it is essential to monitor the occupational exposure for workers. Such surveillance has mainly been performed by air monitoring. However, biological monitoring may be an alternative methodology in exposure assessment because it holds several advantages when compared with air monitoring. The sampling is more convenient, and biomarkers with long half-times, such as protein adducts, may be used to monitor long-term exposure, which is time-consuming to perform with air monitoring. Furthermore, biomarkers reflect the absorbed dose that integrates such factors as lung ventilation, alternative routes of exposure, and genetic and acquired metabolic characteristics. Thus biomarker levels, rather than air levels, may better correlate with systemic adverse health effects, such as cancer or sensitization. However, it is not clear whether the isocyanate-induced irritative effects in the airways depend on the air concentration, the actual inhaled dose, or the systemically absorbed dose.

Absorbed TDI forms protein adducts in blood, preferentially with serum albumin in plasma and with hemoglobin in erythrocytes $(5,6)$. The TDI metabolites are excreted in urine as low-molecular-weight compounds (7). Through the hydrolysis of biological samples from TDI-exposed subjects, the 2,4-TDI- and 2,6-TDI-related metabolites are released as 2,4- and 2,6-toluenediamine (2,4-TDA

1 Department of Occupational and Environmental Medicine, University Hospital, Lund, Sweden.

Reprint requests to: Mr Carl Johan Sennbro, Institute of Laboratory Medicine, Department of Occupational and Environmental Medicine, University Hospital, S-221 85 Lund, Sweden. [E-mail: carl-johan.sennbro@ymed.lu.se] 
and 2,6-TDA), respectively. Several methods for quantifying these biomarkers have been described, but only a few studies have concerned the addressed interpretation of the biomarkers as measures of exposure. These earlier studies were performed in only one or two plants, and there were few workers. None of these studies included data on both urinary and blood biomarkers $(6,8,9,10)$.

In our present study, our main objective was to evaluate both urinary and plasma biomarkers of exposure to TDI further in a large group of workers from various work environments, in order to establish quantitative methods for the biological monitoring of TDI.

Table 1. Biological samples obtained from the workers exposed to toluene diisocyanate (TDI) and the unexposed workers. (U1 = urinary samples obtained on the day of air monitoring, U2 and P = urinary and plasma samples, respectively, obtained in connection with a medical examination performed within 2 weeks of the day of the air monitoring)

\begin{tabular}{lcrrrrrr}
\hline Group & U1, & U1, & U2, & $\begin{array}{l}\text { U1, } \\
\text { U2, }\end{array}$ & $\begin{array}{c}\text { Only } \\
\text { U1 }\end{array}$ & $\begin{array}{c}\text { Only } \\
\text { U2 }\end{array}$ & $\begin{array}{c}\text { Only } \\
\text { U2 }\end{array}$ \\
\hline Exposed $(\mathrm{N}=81)$ & 60 & 4 & 1 & 3 & 13 & - & - \\
Unexposed $(\mathrm{N}=121)$ & - & - & 117 & - & - & 3 & 1 \\
\hline
\end{tabular}

Table 2. Levels of toluene diisocyanate (TDI) biomarkers in the biological samples obtained from the exposed and unexposed workers. (U1 = urinary samples obtained on the day of air monitoring, TDA = toluenediamine, tot = total, U2 and P = urinary and plasma samples, respectively, obtained in connection with a medical examination performed within 2 weeks of the day of the air monitoring)

\begin{tabular}{lccc}
\hline Group & \multicolumn{3}{c}{ Biomarker levels } \\
\cline { 2 - 4 } & $\begin{array}{c}\text { Range } \\
(\mu \mathrm{g} / \mathrm{l})\end{array}$ & $\begin{array}{c}\text { Median } \\
(\mu \mathrm{g} / \mathrm{l})\end{array}$ & $\begin{array}{c}\text { Median a } \\
(\mu \mathrm{g} / \mathrm{g} \text { creatinine })\end{array}$ \\
\hline Exposed workers & & & \\
U1 2,4-TDA & $<0.1-47$ & 4.5 & 3.8 \\
U1 2,6-TDA & $<0.1-115$ & 3.7 & 3.4 \\
U1 tot-TDA & $<0.1-162$ & 9.7 & 6.9 \\
U2 2,4-TDA & $<0.1-76$ & 4.7 & 3.7 \\
U2 2,6-TDA & $<0.1-40$ & 5.3 & 4.1 \\
U2 tot-TDA & $<0.1-116$ & 11 & 8.3 \\
P 2,4-TDA & $<0.1-31$ & 7.4 & $\cdot$ \\
P 2,6-TDA & $<0.1-42$ & 6.1 & $\cdot$ \\
P tot-TDA & $<0.1-70$ & 14 & $\cdot$ \\
Unexposed workers & & & \\
U1 2,4-TDA &. &. & $\cdot$ \\
U1 2,6-TDA & $\cdot$ & $\cdot$ & $\cdot$ \\
U1 tot-TDA & $\cdot$ & $\cdot$ & $\cdot$ \\
U2 2,4-TDA & $<0.1-0.4$ & $<0.1$ & $<0.1$ \\
U2 2,6-TDA & $<0.1-0.2$ & $<0.1$ & $<0.1$ \\
U2 tot-TDA & $<0.1-0.4$ & $<0.1$ & $<0.1$ \\
P 2,4-TDA & $<0.1-0.1$ & $<0.1$ & $\cdot$ \\
P 2,6-TDA & $<0.1-0.1$ & $<0.1$ & $\cdot$ \\
P tot-TDA & $<0.1-0.1$ & $<0.1$ & $\cdot$ \\
\hline
\end{tabular}

a The median of the urinary biomarker levels is also given in $\mu \mathrm{g} / \mathrm{g}$ creatinine to facilitate comparisons with the results of earlier studies (9).

\section{Study population and methods}

\section{Plants and workers}

The study included 81 exposed workers from nine plants in southern Sweden. The plants, previously described in detail (11), were five molding plants, two flame lamination plants, and two plants with low- or nonheating processes, all using either TDI or TDI-based polyurethane. The age range of the exposed workers was 18-63 (median 36) years, and $81 \%(\mathrm{~N}=66)$ were men. The workload was considered to be moderate for all the exposed workers.

The study also included a reference group consisting of 121 unexposed workers, previously described (Sennbro et al, submitted). The age range of the unexposed workers was 20-63 (median 42) years and $49 \%(\mathrm{~N}=59)$ were men. The study was approved by the ethics committee of the Lund University, Sweden, and it was performed with the written informed consent of the workers.

\section{Collection of samples}

Air samples were collected using filters impregnated with 1-(2-methoxyphenyl)piperazine (2MP) (12) during one workshift for each exposed worker. In principle, two consecutive filters, each sampled for approximately 4 hours, were used to monitor the whole-day personal exposure to TDI. The median time used for the personal monitoring was 7.5 hours. When personal protection equipment was used, a pause was made in the air sampling. Immediately after the sampling, the filters were desorbed in toluene containing 2MP, and they were stored with protection from light. Upon arrival in the laboratory, the samples were stored in a refrigerator until the analysis. No air monitoring was performed for the reference group.

On the day of the air monitoring, a urinary sample (U1) was collected from 80 of the exposed workers. In connection with a medical examination performed within 2 weeks of the air monitoring, a second urinary sample (U2) and a blood sample were collected from 64 and 65 of the exposed workers, respectively. For the reference group, 120 urinary and 118 blood samples were collected in a corresponding medical examination. A summary of all the collected biological samples is given in table 1 . The biomarker levels, previously partly described (13), are presented in table 2.

The urinary samples were collected as one pooled sample for each worker during the last 4 hours of the workshift. The blood samples were collected by arm-vein puncture, in Venoject ${ }^{\circledR}$ blood sampling tubes containing heparin. After 
arrival in the laboratory, the plasma was separated from the blood cells by centrifugation. The biological samples were then stored at $-20^{\circ} \mathrm{C}$ until the day of the analysis.

\section{Analysis}

The airborne 2,4-TDI and 2,6-TDI, sampled on the 2MP filters, were quantified by high-performance liquid chromatography and tandem mass spectrometry as previously described (14), with the exception that a deuterium-labeled internal standard was used. The limit of quantification (LOQ) was $20 \mathrm{ng} / \mathrm{sample}$. According to a previous evaluation of the 2MP method (15), the quantified amounts of TDI need to be corrected for losses during sampling. Thus a sampling time-dependent correction factor of $(k \times t) /\left(1-e^{-k t}\right)$ was used to adjust for long-term sampling errors, where $t$ is the sampling time in hours, and the constant $k$ is 0.30 $\mathrm{h}^{-1}$ for 2,4-TDI and $0.23 \mathrm{~h}^{-1}$ for 2,6-TDI. Furthermore, a factor of 1.11 adjusts for systematic errors in the short-term sampling of 2,4-TDI, as compared with an impinger method with dibutylamine. No such systematic errors were observed for 2,6TDI. By multiplying these correction factors with the measured air levels, the personal 8-hour timeweighted-average (TWA) air levels of 2,4- and 2,6TDI were obtained. These corrected air levels are referred to as A-2,4-TDI and A-2,6-TDI, respectively, or as A-tot-TDI when the two isomer levels are added together. The range of the air levels in the data was $<\mathrm{LOQ}-19 \mu \mathrm{g} / \mathrm{m}^{3}$ (median $2 \mu \mathrm{g} / \mathrm{m}^{3}$ ) for 2,4-TDI, <LOQ-26 $\mu \mathrm{g} / \mathrm{m}^{3}$ (median $2 \mu \mathrm{g} / \mathrm{m}^{3}$ ) for 2,6-TDI, and <LOQ-44 $\mu \mathrm{g} / \mathrm{m}^{3}$ (median $4 \mu \mathrm{g} / \mathrm{m}^{3}$ ) for the sum of the isomers.

The biomarker levels in the urinary and plasma samples were analyzed according to Sennbro et al (13). In principle, the biological samples were hydrolyzed for 24 hours in $0.3 \mathrm{M}$ of sodium hydroxide to release the TDI-related diamines 2,4-TDA and 2,6-TDA. The diamines were extracted with toluene, and, after derivatization with pentafluoropropionic acid anhydride, the derivatives were quantified by gas chromatography and mass spectrometry. Each sample was analyzed at least twice, and the precision was $7-18 \%$. The limit of detection (LOD) was $0.1 \mathrm{ng} / \mathrm{ml}$. The levels of 2,4-TDA and 2,6-TDA in the hydrolyzed samples are referred to with the prefixes U-, U1- or U2- for the urinary samples and with $\mathrm{P}$ - for the plasma samples. The levels of the sum of 2,4-TDA and 2,6-TDA in the hydrolyzed samples are denoted as "tot-TDA". The density of the urinary samples was determined by a hand refractometer (Atago URC-PN) and the uri- nary creatinine concentration by the modified Jaffe's method (16).

\section{Calculations and statistics}

Correlations between the air exposure and the biomarkers. For the exposed workers, the associations between the biomarkers, on one hand, and the personal 8-hour TWA air exposure, on the other, were analyzed by calculations of the Pearson correlation coefficients (r) and Spearman's rank correlation coefficients $\left(r_{s}\right)$. These calculations were performed on both the individual and the group level, where the workers were grouped according to their plant. The total number of workers was 81 , of which 80 , 64 , and 65 were included when the air levels were correlated with the U1-, U2- and P- biomarker levels, respectively. Calculations on the group level were based on the mean of the biomarker and air levels. In each calculation, there were nine groups consisting of between 2 and 24 workers each. All the workers were exposed to TDI, but for 5 and 1 of the workers, respectively, the air level of 2,4TDI or 2,6-TDI was below the LOQ. For 1 worker the biomarker levels of 2,4-TDI, as well as 2,6TDI, were below the LOD. In the analysis, the levels of these workers were set at half the LOQ and LOD, respectively. Unadjusted urinary results were used in the statistical analysis.

Biological exposure limits. Biological exposure limits were calculated for the biomarkers of TDI in

Table 3. Pearson correlation coefficients ( $r$ ) and Spearman's rank correlation coefficients $\left(r_{s}\right)$ for the associations between the personal air and biomarker levels of toluene diisocyanate (TDI) for the exposed workers. For the evaluation of the group data, the number of groups were nine in all cases. $(A=$ air, $\mathrm{U} 1=$ urinary samples obtained on the day of air monitoring, TDA = toluenediamine, U2 and $P=$ urinary and plasma samples, respectively, obtained in connection with a medical examination performed within 2 weeks of the day of the air monitoring)

\begin{tabular}{lccccccc}
\hline Exposure & \multicolumn{3}{c}{ Individuals } & & \multicolumn{2}{c}{ Groups } \\
\cline { 2 - 4 } \cline { 6 - 7 } & $\mathrm{N}$ & $\mathrm{r}$ & $\mathrm{r}_{\mathrm{s}}$ & & $\mathrm{r}$ & $\mathrm{r}_{\mathrm{s}}$ \\
\hline A-2,4-TDI & & & & & \\
U1-2,4-TDA & 80 & 0.83 & 0.75 & & 0.92 & 0.97 \\
U2-2,4-TDA & 64 & 0.49 & 0.43 & & 0.71 & 0.82 \\
P-2,4-TDA & 65 & 0.53 & 0.50 & & 0.72 & 0.73 \\
A-2,6-TDI & & & & & & \\
U1 2,6-TDA & 80 & 0.88 & 0.76 & & 1.00 & 1.00 \\
U2 2,6-TDA & 64 & 0.62 & 0.65 & & 0.68 & 0.97 \\
P 2,6-TDA & 65 & 0.75 & 0.78 & & 0.86 & 0.92 \\
A-tot-TDI & & & & & & \\
U1 tot-TDA & 80 & 0.87 & 0.75 & & 0.97 & 0.97 \\
U2 tot-TDA & 64 & 0.63 & 0.58 & & 0.76 & 0.97 \\
P tot-TDA & 65 & 0.65 & 0.68 & & 0.82 & 0.80 \\
\hline
\end{tabular}


urine and plasma by linear regression analysis. The biological exposure limit is an estimation of the biomarker level that corresponds to the 8-hour TWA exposure to TDI at the Swedish occupational exposure limit (OEL) in air $\left(5 \mathrm{ppb} ; 36 \mu \mathrm{g} / \mathrm{m}^{3}\right)$. Biological exposure limits were calculated for both the urinary and plasma biomarkers of 2,4-TDI, 2,6TDI and for tot-TDI. The calculations were based on the corrected air levels and biomarker levels in the $\mathrm{U} 1$ and $\mathrm{P}$ samples of the exposed workers and the biomarker levels in the $\mathrm{U} 2$ and $\mathrm{P}$ samples of the unexposed workers. In the linear regression analysis, the biomarker level was set as half the LOD for the workers with biomarker levels below the LOD, and the air levels were set as half the LOQ for those with air levels below the LOQ and for the unexposed workers. The regression curves were weighted by $1 / \mathrm{X}$, where the independent variable $\mathrm{X}$ was the air levels. The biological exposure limits were calculated by extrapolation up to $36 \mu \mathrm{g} / \mathrm{m}^{3}$ of each of the obtained linear regression curves.

Individual interday variation of the urinary biomarker levels. The individual interday variation in the urinary biomarkers $(\mathrm{N}=63)$, as determined in the $\mathrm{U} 1$ and $\mathrm{U} 2$ samples, were calculated as the relative deviation, $\left.\left(\left|\mathrm{X}_{1}-\mathrm{X}_{2}\right|\right) / \mathrm{X}_{\text {mean }}\right)$, where $\mathrm{X}_{1}$ and $\mathrm{X}_{2}$ are the biomarker levels in the $\mathrm{U} 1$ and $\mathrm{U} 2$ samples, respectively, and $\mathrm{X}_{\text {mean }}$ equals the mean of $\mathrm{X}_{1}$ and $\mathrm{X}_{2}$. The systematic differences in the biomarker levels in the U1 and $\mathrm{U} 2$ samples were analyzed by a paired t-test and the Wilcoxon signed ranked test.
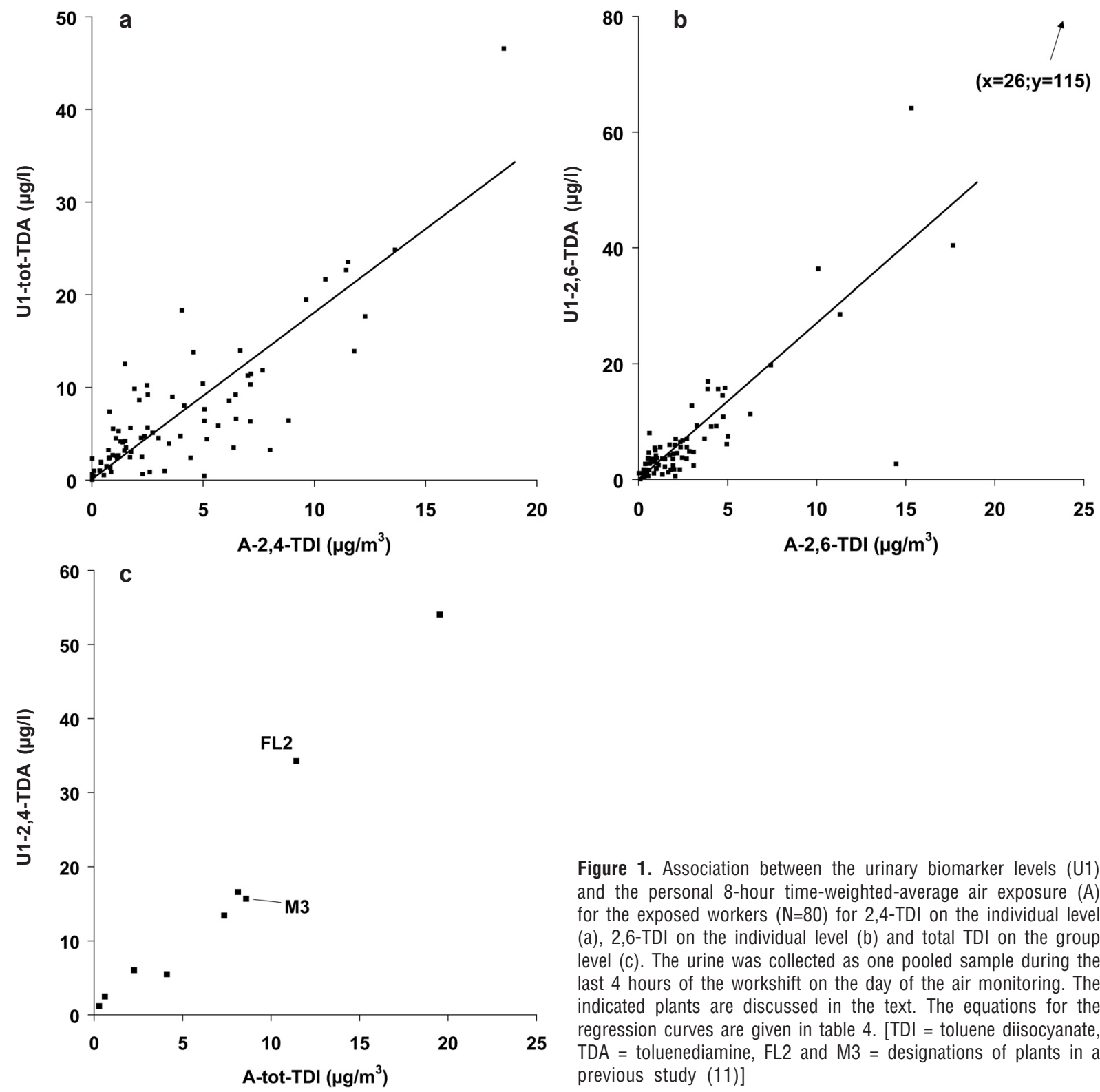

Figure 1. Association between the urinary biomarker levels (U1) and the personal 8-hour time-weighted-average air exposure $(A)$ for the exposed workers $(\mathrm{N}=80)$ for 2,4-TDI on the individual level (a), 2,6-TDI on the individual level (b) and total TDI on the group level (c). The urine was collected as one pooled sample during the last 4 hours of the workshift on the day of the air monitoring. The indicated plants are discussed in the text. The equations for the regression curves are given in table 4. [TDI = toluene diisocyanate, TDA = toluenediamine, FL2 and M3 = designations of plants in a previous study (11)] 


\section{Results}

Correlations between the air exposure and the biomarkers

The calculated correlation coefficients $r$ and $r_{s}$ for the correlation between the TDI biomarker levels and the TDI air levels are presented in table 3 on page 373 for the individuals and the groups. In figure 1 on page 374 and figure 2 on page 375, the biomarker levels in urine and plasma, respectively, are plotted against the personal 8-hour TWA air-exposure levels on both the individual and the group level. Generally, the air levels correlated better with the biomarkers in the U1 samples than with the biomarkers in the $\mathrm{U} 2$ and $\mathrm{P}$ samples.

\section{Biological exposure limits}

The calculated linear regression curves for the associations between the personal air levels of TDI and the levels of the biomarkers of TDI and the biological exposure limits are presented in table 4 on page 376. The biological exposure limits were higher for 2,6-TDI than for 2,4-TDI.

\section{Individual interday variation in the urinary biomarker levels}

The relative deviation was $0-183 \%$ (median $50 \%$ ) for urinary 2,4-TDA and $0-152 \%$ (median 49\%) for urinary 2,6-TDA. There were no systematic differences between the biomarker levels in the U1 and $\mathrm{U} 2$ samples.
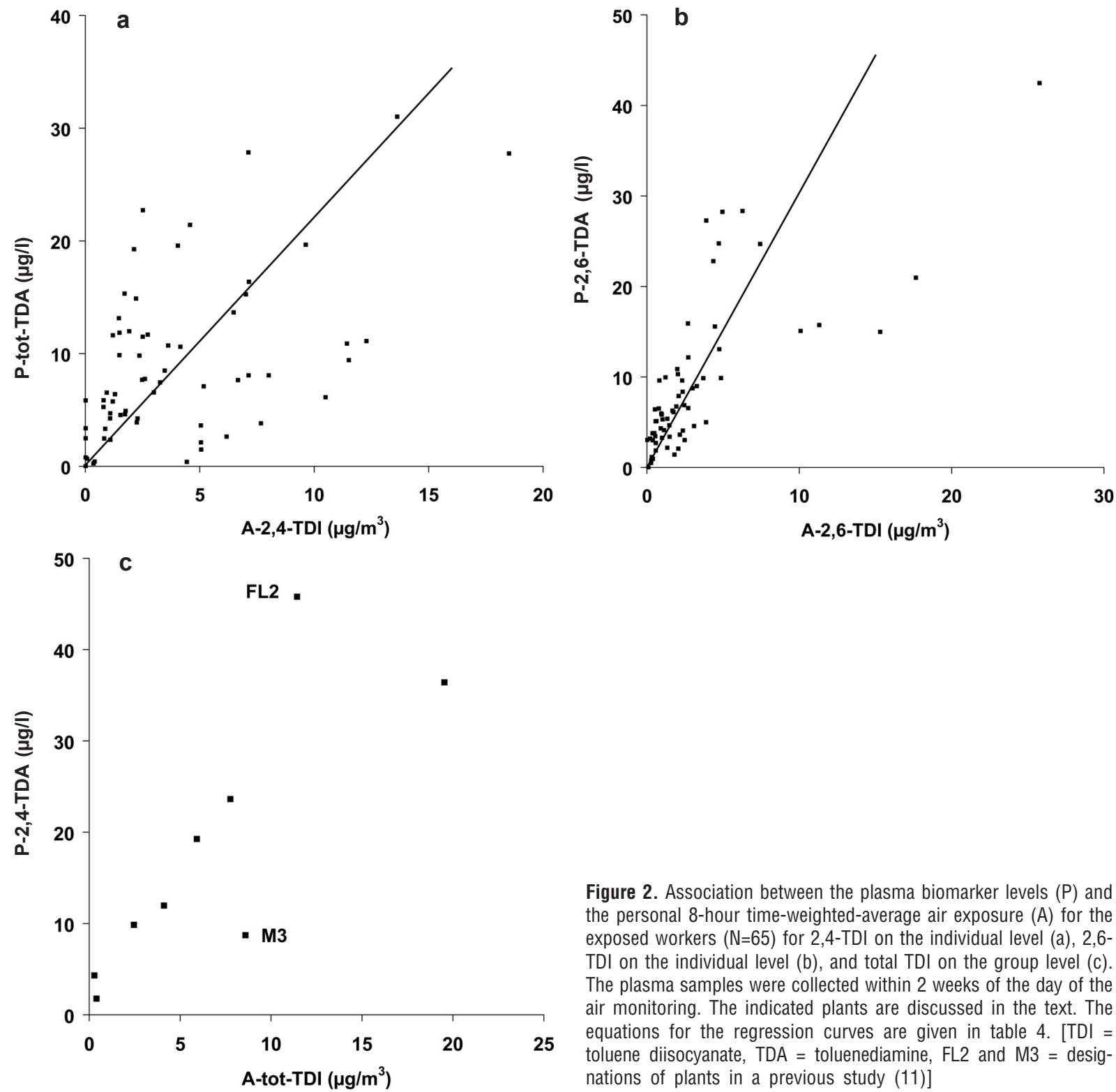

Figure 2. Association between the plasma biomarker levels $(P)$ and the personal 8-hour time-weighted-average air exposure $(A)$ for the exposed workers $(\mathrm{N}=65)$ for 2,4-TDI on the individual level (a), 2,6TDI on the individual level (b), and total TDI on the group level (c). The plasma samples were collected within 2 weeks of the day of the air monitoring. The indicated plants are discussed in the text. The equations for the regression curves are given in table 4. [TDI = toluene diisocyanate, TDA = toluenediamine, FL2 and M3 = designations of plants in a previous study (11)] 
Table 4. Linear regression curves for the associations between the personal 8-hour time-weighted-average (TWA) air levels (A) of toluene diisocyanate (TDI) and the corresponding biomarkers in urine $(U)$ a and plasma $(P)$ for the exposed and unexposed workers. The calculated biological exposure limits (BEL) are also given. $(\mathrm{U}=$ urinary samples, TDA = toluenediamine, $\mathrm{U} 1$ = urinary samples obtained on the day of air monitoring, U2 and $P=$ urine and plasma samples, respectively, obtained in connection with a medical examination performed within 2 weeks of the day of the air monitoring, tot $=$ total, $95 \% \mathrm{Cl}=95 \%$ confidence interval)

\begin{tabular}{lccccc}
\hline Exposure & $N$ & $\begin{array}{c}\text { Curve } \\
\text { equation }{ }^{b}\end{array}$ & $\begin{array}{c}95 \% \mathrm{Cl} \\
\text { for the } \\
\text { slope }\end{array}$ & $\begin{array}{r}\mathrm{BEL}{ }^{\mathrm{c}} \\
\begin{array}{c}95 \% \mathrm{Cl} \\
\text { for } \\
\mathrm{BEL}\end{array}\end{array}$ \\
\hline A 2,4-TDI & & & & & \\
U 2,4-TDA & 200 & $\mathrm{y}=1.8 \cdot x+0.1$ & $1.6-2.0$ & 65 & $58-72$ \\
P 2,4-TDA & 183 & $\mathrm{y}=2.2 \cdot x+0.1$ & $1.7-2.8$ & 79 & $61-98$ \\
A 2,6-TDI & & & & & \\
U 2,6-TDA & 200 & $y=2.7 \cdot x+0.02$ & $2.5-2.9$ & 97 & $90-105$ \\
P 2,6-TDA & 183 & $y=2.9 \cdot x+0.03$ & $2.5-3.2$ & 104 & $92-117$ \\
A tot-TDI & & & & & \\
U tot-TDA & 200 & $y=2.2 \cdot x+0.1$ & $2.2-2.9$ & 79 & $72-86$ \\
P tot-TDA & 183 & $y=2.5 \cdot x+0.1$ & $2.0-2.4$ & 90 & $76-104$ \\
\hline
\end{tabular}

a For the exposed workers, the biomarker levels in the U1 samples were used, and for the unexposed workers the biomarker levels in the U2 samples were used.

b The y variable in the equations corresponds to the measured biomarker level in $\mu \mathrm{g} / \mathrm{l}$ and the $x$ variable corresponds to the personal 8-hour TWA air exposure in $\mu \mathrm{g} / \mathrm{m}^{3}$. The unit for the slopes is $\mathrm{m}^{3} / \mathrm{l}$. All regression curves were weighted by $1 / x$.

${ }^{c}$ The BEL is the biomarker level corresponding to a personal 8-hour TWA air exposure to TDI at the present Swedish occupational exposure limit ( $5 \mathrm{ppb} ; 36 \mu \mathrm{g} / \mathrm{m}^{3}$ ). The BEL levels are given as $\mu \mathrm{g} / \mathrm{l}$ in plasma or in urine collected as a pooled sample during the last 4 hours of a workshift.

\section{Discussion}

In our study we have shown that biomarkers for TDI in urine and plasma can be used for the quantitative biological monitoring of occupational exposure. We have also proposed biological exposure limits for TDI.

The Swedish occupational exposure limits for air exposure to TDI are $10 \mathrm{ppb}\left(72 \mu \mathrm{g} / \mathrm{m}^{3}\right)$ and 5 ppb $\left(36 \mu \mathrm{g} / \mathrm{m}^{3}\right)$ on the basis of 5 -minute and 8 hour TWA exposure, respectively. Many other countries have the same or similar occupational exposure limits. Air monitoring is suitable for the control of the short-term exposure limit but is less convenient for long-term exposure assessment as compared with biological monitoring. Thus, in order to develop methods for biological monitoring, we assessed the whole-day air exposure concomitant to the collection of biological samples.

In the statistical analysis, the air levels measured by the 2MP method were corrected according to previously described correction factors (15). The calculation of the factors was based on limited data, and it has not been further corroborated. However, it was found that long-term sampling with the 2MP method clearly underestimated the air levels of TDI (15).
The strategy for the urinary sampling was based on two previous observations. First, the levels of the urinary biomarkers vary both within and between days for individual workers $(17,18)$. Second, the urinary elimination half-time of the biomarkers derived from recent exposure to TDI is about 2-8 hours (18-20). According to a nomogram presented by Droz et al (21), such biomarkers should mainly reflect the exposure during the day of sampling. Thus by pooling the sampling during the last 4 hours of a workshift, the withinday variation of the biomarker levels should be smoothed out, and they mainly reflect recent exposure. Furthermore, by sampling on different days, the variation in the exposure can be evaluated. On the other hand, the urinary levels are also believed to be a measure of long-term exposure to TDI, as they depend on the elimination of protein adducts. This assumption is supported by the high correlation between urinary and plasma biomarker levels found by Sennbro et al (13).

As shown in table 3 and figure 1, there were strong associations between the urinary biomarker levels and the air exposure. The large individual deviation from the linear curve was expected, and it was diminished by separating the workers into groups. The biomarkers in the U1 samples correlated to a much higher degree with the air levels than the biomarkers in the U2 samples did. This result shows that the urinary levels mainly reflect exposure during the day of sampling. Therefore, the large individual interday variation of the urinary biomarkers probably reflects variation in exposure. The U2 samples were collected on the day of the medical examination, which lasted for about 1 hour during the workshift. Still, there were no systematic differences in the exposure between the 2 days of the urine sampling, according to the urinary biomarker levels.

The air measurements were used as reference for the external exposure assessment. The high correlation between the air and urinary levels shows that routes of absorption other than inhalation were of minor importance.

Due to variations in the urine dilution, urinary biomarker levels are often expressed as the excretion rate or are adjusted either according to density or to creatinine content. In this study, there was no clear indication that any adjustment of the urinary levels would improve the correlations against the air exposure to TDI. Rather, the correlation coefficients were decreased (not shown). In addition, as the degree of active secretion across the tubules for the TDI biomarkers are unknown, adjustment for the creatinine content was not an obvious choice. 
In such a case, it is recommended to use the method of expression that provides the best correlation with exposure (22). Hence we concluded that making any adjustments would only add another source of uncertainty, and we used the unadjusted urinary levels in the evaluations.

The air levels generally correlated better with the biomarker levels in the urine than with those in the plasma. This observation was to be expected in that biomarker levels in plasma reflect exposure during at least 1 month back in time, since the elimination half-time in plasma for TDI biomarkers has been estimated to be about 21 days (18). As air exposure was only assessed during one specific day, any deviation from normal exposure during that day would have decreased the air-plasma correlation. There were major deviations for two of the plants, designated M3 and FL2 in a previous study (11), which are labeled in figures $1 \mathrm{c}$ and $2 \mathrm{c}$. At plant M3, the production load and the relative amount of TDI used in the production was higher than normal, and at plant FL2 the production load was lower than normal due to production and delivery failures. These plants deviate from a presumed linearity for the association between air and plasma biomarker levels (figure 2c); such deviation is not observed for the association between air and urinary biomarker levels (figure 1c).

The number of observations was not equally distributed over the whole range of air and biomarker levels. Thus both $r$ and $r_{s}$ are given in table 3 to describe the correlations. However, no large differences were found between the two methods.

As can be seen in figures $1 a-b$ and $2 a-b$, the variance in the $y$-variable is not the same over the whole range of the $\mathrm{x}$-variable. Thus, a regression analysis performed with y measured on the logarithmic scale may be more appropriate. However, the standardized residuals for the data did not clearly support a logarithmic transformation. Furthermore, the models obtained by linear regression analysis of the logarithmic data were so far from linearity (not shown) that they were difficult to interpret from a physiological point of view. Therefore, linear regression was performed on the untransformed data. In order to get a comprehensive output when backcalculating a biomarker level to an air exposure, we forced the regression curves closer to the origin by weighting the data by $1 / x$. This weighting is also likely to eliminate much of the problem related to the observed differences in variance in $y$ over the whole range of $x$. From these curves different biological exposure limits were obtained.

Biological exposure limits have mainly been proposed in the United States and Germany. However, these countries have different approaches in how to establish the values (23). In the United States, the recommended biological exposure indices (BEI) are always established on the basis of an occupational air-exposure limit by the American Conference of Governmental Industrial Hygienists (ACGIH). In Germany, more directly health-based biological tolerance values (BAT) are established by the German Research Foundation. For diisocyanates, only one biological exposure limit has been established, for 4,4'-methylenediphenyl diisocyanate, for which Germany has applied a BAT of $10 \mu \mathrm{g} / \mathrm{g}$ creatinine, using 4,4'-diaminodiphenylmethane in hydrolyzed urine as the biomarker of exposure. For TDA in hydrolyzed urine as a biomarker for TDI exposure, a BEI of about $20 \mu \mathrm{g} / \mathrm{g}$ creatinine has previously been estimated by Maitre et al (9).

In our study we propose biological limits of the BEI type for TDI, by extrapolation of the regression curves up to $36 \mu \mathrm{g} / \mathrm{m}^{3}$. In our data, one worker was exposed to tot-TDI above the occupational exposure limit. Only that worker had biomarker levels above the calculated biological exposure limit in urine and plasma.

When the models in table 4 are used in exposure assessment, our recommendation is to use both urinary and plasma samples. Urinary samples should be used when comparing the back-calculated air level with an occupational exposure limit, since it reflects the 8-hour TWA exposure directly. The plasma biomarkers cannot be used for that purpose but may nevertheless be used as indicators of exposure. It would also be beneficial to perform repeated sampling. Furthermore, data can be used on the group level to estimate the average air levels in the workplace (figure 1c and 2c). Moreover, the back-calculated air-exposure levels should not be overinterpreted, since our calculated models and biological exposure limits are estimates with certain uncertainties, which are obvious from figures 1 and 2. In a recent study (Sennbro et al, submitted), upper reference limits (ie, the biomarker level above which a person is classified as exposed) were calculated. It may be useful to compare biomarker levels with our presented biological exposure limits and upper reference limits.

For urinary biomarkers, the timing of the sampling is crucial for comparison in the presented model, and the urine should thus be sampled as one pooled sample during the last 4 hours of the workshift. In addition, it is important to use $0.3 \mathrm{M}$ of sodium hydroxide when the biological samples are hydrolyzed in the work-up procedure, as described (13), since the recovery of biomarkers depends on the hydrolysis conditions. 
In our study we have shown that we are able to interpret the biomarker levels as an index of airexposure levels. We have also proposed biological exposure limits. These results can support the use of biological monitoring in the occupational exposure assessment of TDI.

\section{Acknowledgments}

Financial support for this work was obtained from the AFA Foundation, Sweden, from the Swedish Council for Work Life and Social Research, and from the Swedish Research Council.

The authors also thank Ms Birgitta Björk, Ms Cecilia Gustavsson, Ms Inger Bensryd, and Ms Kerstin Diab-Kronholm for their skillful technical and medical assistance, Dr Jonas Björk for the statistical consultations, Dr Anders Östin at the National Institute for Working Life North in Umeå, Sweden, for analyzing the air samples, and all the workers in the study for their invaluable participation.

\section{References}

1. Klees JE, Ott MG. Diisocyanates in polyurethane plastics applications. Occup Med 1999;14:759-76.

2. Vandenplas O, Malo J-L, Saetta M, Mapp CE, Fabbri LM. Occupational asthma and extrinsic alveolitis due to isocyanates: current status and perspectives. $\mathrm{Br} \mathrm{J}$ Ind Med 1993;50:213-28.

3. Baur X, Marek W, Ammon J, Czuppon AB, Marczynski B, Raulf-Heimsoth M, et al. Respiratory and other hazards of isocyanates. Int Arch Occup Environ Health 1994; 66:141-52.

4. Ott MG, Diller WF, Jolly AT. Respiratory effects of toluene diisocyanate in the workplace: a discussion of exposure-response relationships. Crit Rev Toxicol 2003; 33:1-59.

5. Lind P, Dalene M, Lindström V, Grubb A, Skarping G. Albumin adducts in plasma from workers exposed to toluene diisocyanate. Analyst 1997;122:151-4.

6. Lind P, Dalene M, Tinnerberg H, Skarping G. Biomarkers in hydrolysed urine, plasma and erythrocytes among workers exposed to thermal degradation products from toluene diisocyanate foam. Analyst 1997;122:51-6.

7. Lind P, Dalene M, Skarping G. Biomarkers of toluene diisocyanate and thermal degradation products of polyurethane, with special reference to the sample preparation. Anal Chim Acta 1996;333:277-83.

8. Rosenberg C, Savolainen H. Determination of occupational exposure to toluene diisocyanate by biological monitoring. J Chromatogr 1986;367:385-92.

9. Maitre A, Berode M, Perdrix A, Romazini S, Savolainen H. Biological monitoring of occupational exposure to toluene diisocyanate. Int Arch Occup Environ Health 1993; 65:97-100.

10. Kääriä K, Hirvonen A, Norppa H, Piirilä P, Vainio H,
Rosenberg C. Exposure to 2,4- and 2,6-toluene diisocyanate (TDI) during production of flexible foam: determination of airborne TDI and urinary 2,4- and 2,6-toluenediamine (TDA). Analyst 2001;126:1025-31.

11. Sennbro CJ, Lindh $\mathrm{CH}$, Östin A, Welinder, Jönsson BAG, Tinnerberg H. A survey of airborne isocyanate exposure in thirteen Swedish polyurethane industries. Ann Occup Hyg 2004;48:405-14.

12. Health and Safety Executive. Organic isocyanates in air, MDHS 25/3. Sudbury (UK): Health and Safety Laboratory, 1999.

13. Sennbro CJ, Lindh $\mathrm{CH}$, Tinnerberg H, Gustavsson C, Littorin M, Welinder H, et al. Development, validation and characterization of an analytical method for quantification of hydrolysable urinary metabolites and plasma protein adducts of 2,4- and 2,6-toluene diisocyanate, 1,5-naphthalene diisocyanate and 4,4'-methylenediphenyl diisocyanate. Biomarkers 2003;8:204-17.

14. Östin A, Sundgren M, Ekman J, Lindahl R, Sundgren M, Levin J-O. Analysis of isocyanates with LC-MS/MS. In: Lesage J, DeGraff ID, Danchik RS, editors. Isocyanates: sampling, analysis and health effects. West Conshohocken (PA): American Society for Testing and Materials; 2002. Special technical publication 1408 .

15. Sennbro CJ, Ekman J, Lindh CH, Welinder H, Jönsson BAG, Tinnerberg H. Determination of isocyanates in air using 1-(2-methoxyphenyl)piperazine impregnated filters; long-term sampling performance and field comparison with impingers with dibutylamine. Ann Occup Hyg 2004;48:415-24.

16. Lustgarten JA, Wenk RE. Simple, rapid, kinetic method for serum creatinine measurement. Clin Chem 1972; 18:1419-22.

17. Persson P, Dalene M, Skarping G, Adamsson M, Hagmar L. Biological monitoring of occupational exposure to toluene diisocyanate: measurement of toluenediamine in hydrolysed urine and plasma by gas chromatography-mass spectrometry. Br J Ind Med 1993;50:1111-8.

18. Lind P, Dalene M, Skarping G, Hagmar L. Toxicokinetics of 2,4- and 2,6-toluenediamine in hydrolysed urine and plasma after occupational exposure to 2,4- and 2,6-toluene diisocyanate. Occup Environ Med 1996;53:94-9.

19. Brorson T, Skarping G, Sangö C. Biological monitoring of isocyanates and related amines-part IV: 2,4- and 2,6-toluenediamine in plasma and urine after test-chamber exposure of humans to 2,4- and 2,6-toluene diisocyanate. Int Arch Occup Environ Health 1991;63:253-9.

20. Skarping G, Dalene M, Sangö C. Biological monitoring of isocyanates related amines. III: test chamber exposure of humans to toluene diisocyanate. Int Arch Occup Environ Health 1991;63:83-8.

21. Droz PO, Berode M, Wu MM. Evaluation of concomitant biological and air monitoring results. Appl Occup Environ Hyg 1991;6:465-74.

22. Boeniger MF, Lowry LK, Rosenberg J. Interpretation of urine results used to assess chemical exposure with emphasis on creatinine adjustments: a review. Am Ind Hyg Assoc J 1993;54:615-27.

23. Morgan MS, Schaller KH. An analysis of criteria for biological limit values developed in Germany and in the United States. Int Arch Occup Environ Health 1999; 72:195-204.

Received for publication: 16 February 2004 